\title{
Axillary and inguinal erythrasma
}

\author{
Irene López Riquelme MD, Elisabeth Gómez Moyano MD PhD
}

Cite as: CMAJ 2021 October 4;193:E1535. doi: 10.1503/cmaj.210310

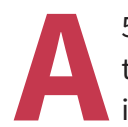

50-year-old man presented to the dermatology department with a 1-year history of itchy axillary and groin lesions. He had been treated with a topical antifungal preparation (cyclopyroxolamin), without improvement, by his family physician, who had suspected fungal intertrigo. On physical examination, we observed wellcircumscribed, erythematous, brownish, scaly plaques affecting both armpits and the groin area bilaterally (Figure 1). To rule out superficial mycoses, we examined skin scrapings from the infected site under direct microscopy after potassium hydroxide preparation. We did not find any signs of fungal infection and did not isolate any dermatophytes in Sabouraud agar.

We suspected bacterial infection. Evaluated under Wood's lamp, the lesions exhibited coralred fluorescence (Figure 2). Gram staining confirmed erythrasma, showing clusters of bacilli in epithelial cells; Corynebacterium minutissimum was isolated in culture. We prescribed topical application of erythromycin gel twice a day, and the skin lesions resolved in 2 weeks.

Erythrasma is a superficial infection caused by Corynebacterium minutissimum. Although it is more frequent in tropical regions, it may be seen in temperate areas in older patients, patients who are obese or patients with diabetes. ${ }^{1}$ Erythrasma typically presents as red-brown macules that coalesce into larger patches, and can be confused with superficial mycoses. Absence of satellite papulopustules is suggestive of erythrasma. ${ }^{2}$ Examination using Wood's lamp facilitates rapid diagnosis because of the characteristic coral-red fluorescence from coproporphyrin III, produced by the bacteria. ${ }^{2,3}$ Propionibacterium acnes may produce a similar colour, and Pseudomonas species fluoresce green. ${ }^{2}$ Recent bathing can temporarily wash away the porphyrins, leading to a negative exam under Wood's lamp. ${ }^{3}$ To confirm the diagnosis, direct microscopy using potassium hydroxide,
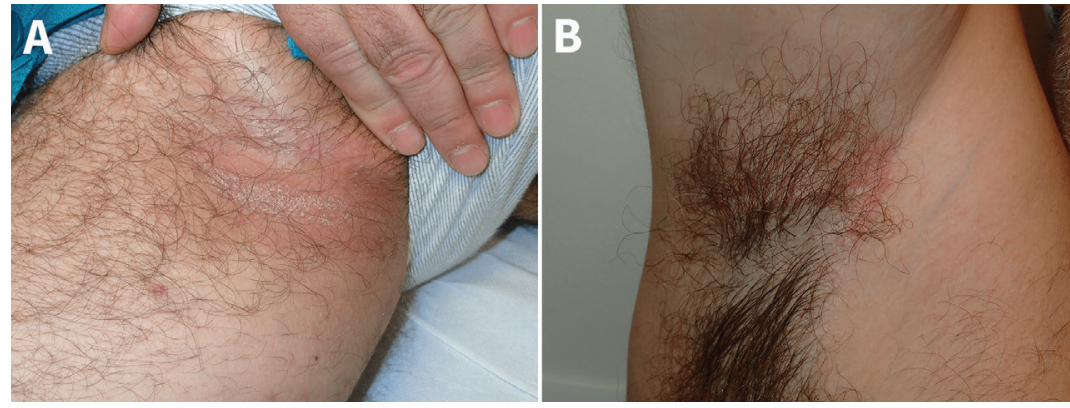

Figure 1: Photographs of a 50-year-old man showing erythematous, brownish scaly plaques affecting (A) groin and (B) armpit.
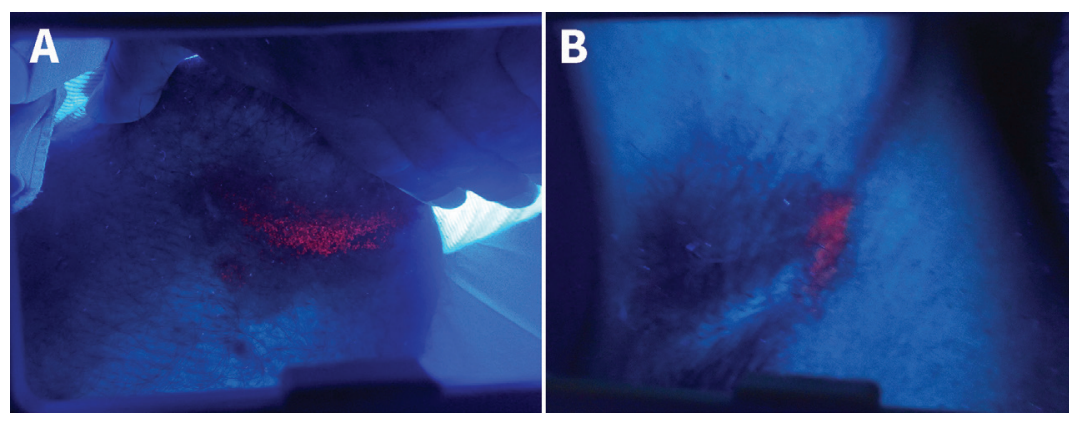

Figure 2: Photographs of (A) groin and (B) axillary lesions showing coral-red fluorescence under Wood's lamp.

Gram stain and culture can be used together to differentiate fungal and Corynebacterium minutissimum infection. ${ }^{1}$ Treatment for erythrasma is erythromycin, either applied topically twice daily until resolution, or $250 \mathrm{mg}$ taken orally 4 times daily for 2 weeks.,

\section{References}

1. Blaise G, Nikkels AF, Hermanns-Lê T, et al. Corynebacterium-associated skin infections. Int J Dermatol 2008;47:884-90.

2. Kalra MG, Higgins KE, Kinney BS. Intertrigo and secondary skin infections. Am Fam Physician 2014;89:569-73.

3. Wilson BB, Wagenseller A, Noland MM. An atypical presentation of erythrasma. J Am Acad Dermatol 2012;67:e217-8.

\section{Competing interests: None declared.}

This article has been peer reviewed.

The authors have obtained patient consent.

Affiliation: Dermatology Department, Hospital Regional Universitario de Málaga, Málaga, Spain
Content licence: This is an Open Access article distributed in accordance with the terms of the Creative Commons Attribution (CC BY-NC-ND 4.0) licence, which permits use, distribution and reproduction in any medium, provided that the original publication is properly cited, the use is noncommercial (i.e., research or educational use), and no modifications or adaptations are made. See: https://creativecommons. org/licenses/by-nc-nd/4.0/

Correspondence to: Irene López Riquelme, lopezriquelmeirene@gmail.com 